\title{
Sanidade de sementes de arroz, biocontrole, caracterização e transmissão de Curvularia lunata em semente-plântula de arroz
}

\author{
Mônica Shirley Brasil dos Santos e Silval, Antônia Alice Costa Rodrigues², \\ Leonardo de Jesus Machado Gois de Oliveira ${ }^{1}$, Erlen Keila Candido e Silva ${ }^{2}$, Tainan dos Santos Pereira ${ }^{3}$ \\ http://dx.doi.org/10.1590/0034-737X201461040009
}

\section{RESUMO}

Este trabalho objetivou avaliar a qualidade sanitária de sementes de arroz, quantificar a transmissão de Curvularia lunata associada à semente e à plântula, e avaliar o efeito dos isolados de Bacillus spp., no controle da mancha foliar, do cultivar Bonança. Para avaliação da sanidade de sementes, as amostras foram desinfestadas e plaqueadas, sendo avaliadas após sete dias de incubação. Na confirmação da patogenicidade, as plântulas foram inoculadas por meio de pulverização e a avaliação da doença ocorreu sete dias após. Na caracterização do isolado de $C$. lunata, foi realizada medição da largura, comprimento e número de septos de 100 conídios. Para a taxa de transmissão de $C$. lunata, foram preparadas 12 bandejas, com 100 sementes cada, de modo a proceder-se às avaliações aos 7, 14, 21 dias após a semeadura (d.a.s.). De cada uma das 100 plântulas, foram separadas as raízes, após sete dias. A inoculação dos isolados de Bacillus foi realizada na forma de suspensão, pulverizada sobre a parte aérea das plântulas. Após uma semana, foi inoculado a $C$. lunata. A avaliação foi efetuada aos 15 dias após inoculação dos isolados patogênicos, medindo-se o tamanho da lesão. No teste de sanidade foi detectada maior incidência de C. lunata (70\%), o qual se apresentou patogênico à variedade de arroz Bonança, sendo detectado em todos os órgãos da plântula. Dentre os isolados de Bacillus, os que mais se destacaram no controle foram B41 (B. Cereus) e B35 (Bacillus sp.), confirmando seu potencial biocontrolador.

Palavras-chave: Oryza sativa L., biocontrole, transmissão de patógeno.

\section{ABSTRACT}

\section{Sanity of rice seed, biocontrol, characterization and transmission of Curvularia lunata on rice seed-seedlings}

This study evaluates the sanitary quality of rice seeds cultivar Bonança, quantifies the transmission of Curvularia lunata associated with seeds - seedling and evaluates the efficiency of Bacillus spp. isolates for the control of leaf spot. The samples were disinfected and plated, and seed health was evaluated after seven days. After confirmation of pathogenicity, the seedlings inoculated by the spraying method and the occurrence of disease was assessed after seven days. For characterization of the $C$. lunata isolate, width and length measurements and number of septa of 100 conidia were taken. We assessed transmission rate of $C$. lunata in 12 trays, each with 100 seeds, and conducted evaluations at 7, 14, 21 days after infection. From each of the 100 seedlings we separated the primary root, the stem and glumes and plated them on PDA for evaluation after seven days. The inoculation of Bacillus isolates was carried out throughaerial spraying of the suspension on the plants. After one week, C. lunata was inoculated and after 15 days

\footnotetext{
Recebido para publicação em 19/02/2013 e aprovado em 04/09/2013.

${ }^{1}$ Engenheiros-Agrônomos. Laboratório de Fitopatologia, Universidade Estadual do Maranhão (UEMA), Caixa Postal 09, 65054-970, São Luís, Maranhão, Brasil. shirleybrasil.85@hotmail.com; leonnardo_jesus@ hotmail.com

${ }^{2}$ Engenheira-Agrônoma, Doutora. Laboratório de Fitopatologia, Universidade Estadual do Maranhão (UEMA), Caixa Postal 09, 65054-970, São Luís, Maranhão, Brasil. aacrodrigues@bol.com.br (autora para correspondência); erlenkeila@yahoo.com.br

${ }^{3}$ Estudante de Agronomia. Laboratório de Fitopatologia, Universidade Estadual do Maranhão (UEMA), 65054-970, Caixa Postal 09, São Luís, Maranhão, Brasil. tainan.tsp@hotmail.com
} 
lesion dimensions were measured. We detected the highest incidence of $C$. lunata (70\%), which was pathogenic to the rice variety Bonança and was detected in all organs of the seedling. Among the isolates of Bacillus, those that stood out in controlling C. lunata were B41 (B. Cereus) and B35 (Bacillus sp.), confirming their potential for biocontrol.

Key words: Oryza Sativa, biocontrol, pathogen transmission.

\section{INTRODUÇÃO}

O arroz (Oryza sativa L.) é o cereal mais cultivado e consumido em todo o mundo. É a fonte alimentar de crescimento mais rápido, na África, e de grande importância para seguridade alimentar em países com renda escassa (FAO, 2004).

As sementes de arroz são responsáveis pela disseminação de inúmeros patógenos que causam importantes doenças nessa cultura. A maioria dos patógenos utiliza as sementes como veículo de transporte e como abrigo para sobrevivência. No Brasil, os fungos constituem-se no mais numeroso e importante grupo de fitopatógenos associados às sementes (Casa et al., 2005), causando prejuízos ao rendimento e à qualidade da cultura.

A mancha dos grãos, causada por um complexo de patógenos (Drechslera oryzae, Phoma sorghina (Sacc.) Boerema, Dorenbosch e Van Kesteren, Alternaria padwickii (Ganguly) M.B. Ellis, Pyricularia grisea, Microdochium oryzae, Sarocladium oryzae (Sawada) W. Gams e D. Hawksw., além de diferentes espécies de Drechslera, Curvularia, Nigrospora, Fusarium, Coniothyrnium, Epicocum, Pithomyces e Chaetomium), depois da brusone (Pyricularia grisea), é uma das principais doenças fúngicas do arroz e vem se tornando problema sério no final do ciclo da cultura. Esta doença ocorre nas lavouras de arroz de todo território brasileiro, provocando perdas de produção, menor qualidade dos grãos e menor rendimento na industrialização. Os sintomas são variáveis, dependendo do patógeno predominante, do estádio de infecção e das condições climáticas (Utumi \& Lobo, 2008). Nas condições climáticas do Maranhão, há predominância de Curvularia lunata (Wakker) Boedijn Meyer, causando a doença. Esses fungos, que pertencem à família Dematiaceae, são considerados mitospóricos.

Várias espécies de Curvularia têm sido relatadas em arroz, entre elas a Curvularia eragrostidis (P. Henn) e Curvularia lunata, como agentes de descoloração, lesão e, ou, deformação de grãos, além de causadores de manchas necróticas em folhas e outras partes da planta, morte de plântulas, etc. (Lima \& Furtado, 2007).

O controle preconizado para a doença é o químico. Entretanto, os impactos negativos decorrentes da utiliza- ção dessa prática tornam necessário o desenvolvimento de alternativas de controle desses fitopatógenos. Dentre as alternativas estudadas, atualmente, destaca- se o controle biológico por meio de antagonistas.

Segundo Kupper et al. (2003), dentre os antagonistas mais estudados atualmente, encontra-se a bactéria Bacillus subtilis Ehrenberg, a qual vem se destacando no controle de doenças do filoplano e em pós-colheita.

Este trabalho objetivou avaliar a qualidade sanitária de sementes, quantificar a transmissão do patógeno associado à semente e à plântula de arroz, do cultivar Bonança, e avaliar o efeito dos isolados de Bacillus spp. no controle de C. lunata, agente da mancha foliar e dos grãos.

\section{MATERIAL E MÉTODOS}

Os experimentos foram conduzidos no Laboratório de Fitopatologia e em casa de vegetação, da Universidade Estadual do Maranhão - UEMA. Foram utilizadas sementes do cultivar Bonança, cedidas pela EMBRAPA Cocais e Planícies Alagáveis.

A avaliação da sanidade das sementes de arroz foi realizada pelo método Blotter test, em que as amostras foram inicialmente desinfestadas, por cinco minutos, por meio de imersão em uma solução de hipoclorito de sódio ( $\mathrm{NaClO})$, a 1,5\% de cloro ativo, seguida de duas lavagens com água destilada e esterilizada.

Em seguida, as sementes foram distribuídas em placas de Petri, esterilizadas, com três camadas de papel de filtro, esterilizado e umedecido com água destilada esterilizada. Foram plaqueadas 400 sementes, de acordo com as Regras de Análise de Sementes (Brasil, 2009), colocando-se 20 sementes por placa. As sementes foram incubadas em condições de fotoperíodo de 12 horas, sob temperatura de $26 \pm 5^{\circ} \mathrm{C}$, durante sete dias (Pinto, 2005). $\mathrm{O}$ levantamento dos patógenos associados às sementes não germinadas e das plântulas foi realizado com auxílio de microscópio estereoscópio (Zeiss com aumento de 40 vezes), após sete dias de incubação. As colônias desenvolvidas sobre as sementes e plântulas foram transferidas para meio de cultura batata-dextrose-ágar (BDA), para viabilizar a identificação, por meio de microculturas. 
Para confirmação da patogenicidade, as plântulas foram obtidas pelo plantio de sementes de arroz do cultivar Bonança, em vasos de três litros, contendo solo previamente esterilizado, e mantidos em casa de vegetação.

No preparo do inóculo de C. lunata, o isolado obtido foi transferido para placas de Petri com meio de cultura BDA, mantidas em condições de laboratório e incubadas por sete dias. Após esse período, foram adicionados $20 \mathrm{~mL}$ de água destilada a cada placa e efetuouse a raspagem das colônias para liberação dos conídios. Em seguida, a concentração da suspensão foi ajustada para $1 \times 10^{5}$ conídios/mL, com o auxílio de câmara de Neubauer. A inoculação das mudas foi feita aos 21 dias, pelo método de pulverização e, após, elas foram mantidas em câmara úmida, por 48 horas. A avaliação da doença foi realizada aos sete dias após a inoculação, com base na Escala Internacional de Lesões, em que: tipo resistente $(\mathrm{R})$ - lesões não necróticas, de cor marrom, cerca de $0,5 \mathrm{~mm}$ de diâmetro; tipo intermediário (I) - lesões de cor cinza, necróticas, tendendo a elípticas, 1-2 mm de comprimento, rodeadas por halo marrom; tipo susceptível (S) - lesões típicas, elípticas, grande centro cinza necrótico, atingindo $10-20 \mathrm{~mm}$ de comprimento, rodeadas por halo marrom (Internacional Rice Research Institute, 1963).

Para essa avaliação, foram amostradas 20 folhas de mesma idade, escolhidas de plantas ao acaso. O experimento foi constituído por 20 vasos, com oito plantas de arroz por vaso.

Para a caracterização do isolado de $C$. lunata, foi efetuado o reisolamento dos fragmentos da parte intermediária das lesões, depois submetidos à desinfestação com álcool $50 \%$, solução hipoclorito de sódio $(\mathrm{NaClO})$ a $5 \%$ e água destilada esterilizada. Os fragmentos foram colocados em placas de Petri, com meio BDA, em quatro pontos equidistantes, mantidas em temperatura ambiente para o crescimento do fungo. A identificação dos isolados foi feita de acordo com aspectos morfológicos e com auxílio de microculturas (Menezes \& Assis, 2004). Foram realizadas medições da largura, comprimento e número de septos de 100 conídios observados em microscópio ótico e medidos com o auxílio de ocular micrométrica, calibrada com micrômetro, ajustada com valor de correção da ocular. Em seguida, foi feito o registro fotográfico das estruturas do fitopatógeno, com câmara digital (Leica LAS EZ), acoplada ao microscópio ótico.

$\mathrm{Na}$ quantificação da taxa de transmissão do fungo $C$., foram utilizadas sementes de arroz, do cultivar Bonança, com uma incidência natural de fungos, sem tratamento com fungicidas (Sartori et al, 2005). A semeadura foi realizada em bandejas, com substrato isento do fungo, constituído pela mistura de solo autoclavado, areia grossa autoclavada e vermiculita, na proporção de 3:1:1. Foram semeadas 12 bandejas com 100 sementes cada, sendo a umidade do substrato mantida na capacidade de campo. As avaliações foram realizadas aos 7, 14 e 21 d.a.s.

Em cada avaliação, 100 plântulas foram coletadas, ao acaso, lavadas em água corrente, para retirada do excesso de solo aderido ao sistema radicular, e levadas ao Laboratório de Fitopatologia. De cada plântula, foram destacadas as estruturas (raiz primária, colmo e gluma) e, em seguida, realizada a assepsia do material, em hipoclorito de sódio (1\%), por $3 \mathrm{~min}$, seguida de lavagem com água destilada esterilizada. Os tecidos vegetais foram colocados em placas de Petri, com meio de cultura BDA e acrescido de antibiótico. O material foi incubado, durante sete dias, em BOD, sob temperatura de $25^{\circ} \mathrm{C}$ e fotoperíodo de $12 \mathrm{~h}$. Foi considerado infectado o órgão em que foi possível identificar a colônia e, ou, estruturas do fungo, sob microscópio estereoscópio.

Os dados foram expressos em taxa de transmissão do fungo da semente para cada órgão da plântula, em função da incidência destes nas sementes (valor obtido na análise sanitária) e estruturas respectivas; a avaliação foi feita em três períodos de tempo. Logo após, determinou-se a percentagem de transmissão de cada patógeno, por meio da fórmula de Goulart (1996):

Transmissão $(\%)=\frac{\% \text { de plântulas com determinado patógeno } \mathrm{x}(100)}{\text { incidência desses patógenos nas sementes }}$

O experimento para avaliação dos isolados de Bacillus em plantas de arroz inoculadas com C. lunata foi conduzido em casa de vegetação da UEMA. Plantas de arroz do cultivar Bonança foram cultivadas em vasos com capacidade de três litros, com solo autoclavado. A inoculação dos isolados de Bacillus foi realizada uma semana após o plantio, por meio da pulverização de suspensão na parte aérea das plantas. A essa suspensão, foi adicionada solução salina $(\mathrm{NaCl} 0,85 \%)$ e a concentração ajustada para $\mathrm{OD}_{540}=0,5$. Foram utilizados nove isolados de Bacillus. Uma semana após a inoculação do antagonista, foi inoculado o patógeno desafiante, por meio da pulverização da parte aérea das plantas com suspensão de $1 \times 10^{5}$ conídios/ $\mathrm{mL}$. Em seguida, as plantas de arroz foram mantidas em câmara úmida e a avaliação foi efetuada 15 dias após a inoculação do patógeno, por meio da medição da lesão, com régua milimetrada. Foi avaliado também o número de folhas por vaso, o número de folhas sadias e o tamanho da folha.

O delineamento estatístico foi inteiramente casualizado, com dez tratamentos, constituídos de isolados de antagonistas, com cinco repetições, e cada vaso constou de uma unidade experimental. A testemunha foi constituída de plantas inoculadas com fitopatógenos. 


\section{RESULTADOS E DISCUSSÃO}

As sementes de arroz do cultivar Bonança apresentaram um percentual de germinação de $88 \%$, sendo $32,75 \%$ de sementes sadias. No teste de sanidade, foi detectada maior incidência de C. lunata (70\%), com menor ocorrência de Fusarium spp. (1,5\% - Figura 1). Os resultados confirmaram a potencialidade das sementes como agentes disseminadores de fitopatógenos.

Uma grande incidência de fitopatógenos em sementes de arroz também foi encontrada por Marassi et al. (2008), que, avaliando 365 amostras produzidas no Maranhão, verificaram a presença de fungos associados às sementes, em todos os lotes analisados, sendo os gêneros Aspergillus e teleomorfos os mais frequentes na microbiota isolada (68\%). Este fato é justificado pelas condições de clima tropical, que aceleram a colonização dos grãos por fungos, aliadas às condições inadequadas de armazenamento de grãos e sementes.

Não foram encontradas sementes infestadas por $P$. grisea. Uma das possíveis causas da ausência de sementes portadoras do patógeno é decorrente do beneficiamento, que elimina sementes chochas e mal formadas, características do ataque do patógeno no campo.

De acordo com os resultados, o fungo $C$. lunata mostrou-se patogênico para variedade de arroz Bonança, cujas plantas apresentaram reação de susceptibilidade ao patógeno (Tabela 1).

Confirmando os resultados deste trabalho, Malavolta et al. (2007) relataram a associação de espécies de fungos como Drechslera spp., Curvularia spp., Nigrospora sp., Fusarium spp., com a mancha dos grãos, em arroz de terras altas.
Segundo Dasgupta (2005) e Shan et al (2008), várias espécies de Curvularia são associadas a doenças em plantas. Shan et al. (2008), trabalhando em 14 áreas de milho, na Província de Hebei, na China, conseguiram isolar C. lunata e, ainda, encontraram C. clavata, $C$. eragrostidis e $C$. intermedia, todos causando doença em cultivares de milho (Zea mays), embora $C$. lunata e $C$. intermedia fossem mais patogênicas que as demais.

$\mathrm{Na}$ caracterização de $C$. lunata, em BDA, a colônia apresentou micélio branco e cotonoso, mudando, posteriormente, para a cor preto-acinzentada. Os conídios observados em lâminas com microscópio óptico apresentaram três septos transversais, com célula mediana mais volumosa, curvatura pronunciada, células das extremidades hialinas e hilo escuro em uma das extremidades.

Na mensuração de 100 conídios, oriundos do crescimento de $C$. lunata, em meio BDA, verificaram-se as dimensões de 5,77 - 11,34 $\mu \mathrm{m}$ de largura e 16,35 - 26,48 $\mu \mathrm{m}$ de comprimento, com média de 8,58 x 20,62 ìm .

Resultados semelhantes foram encontrados por Lima \& Furtado (2007), em trabalho em que os fungos apresentaram conídios solitários, 3-septados; terceira célula a partir da base, maior e, por vezes, mais escura, frequentemente curvos na terceira célula, que pode surgir verrugosa; septos simples, claviformes, elipsoides ou fusiformes, cicatriz truncada, células das extremidades castanho-claras a sub-hialinas, 18-31 x 9-15 ìm. Colônias efusas, de pulverulentas a feltrosas, com densidade média, de cinzentas a negras, com frente de crescimento regular e ausência de zonagem. Os mesmos autores afirmaram, ainda, que, o gênero Curvularia tem características bem evidentes, o que torna sua identificação por meio de características morfológicas relativamente simples.
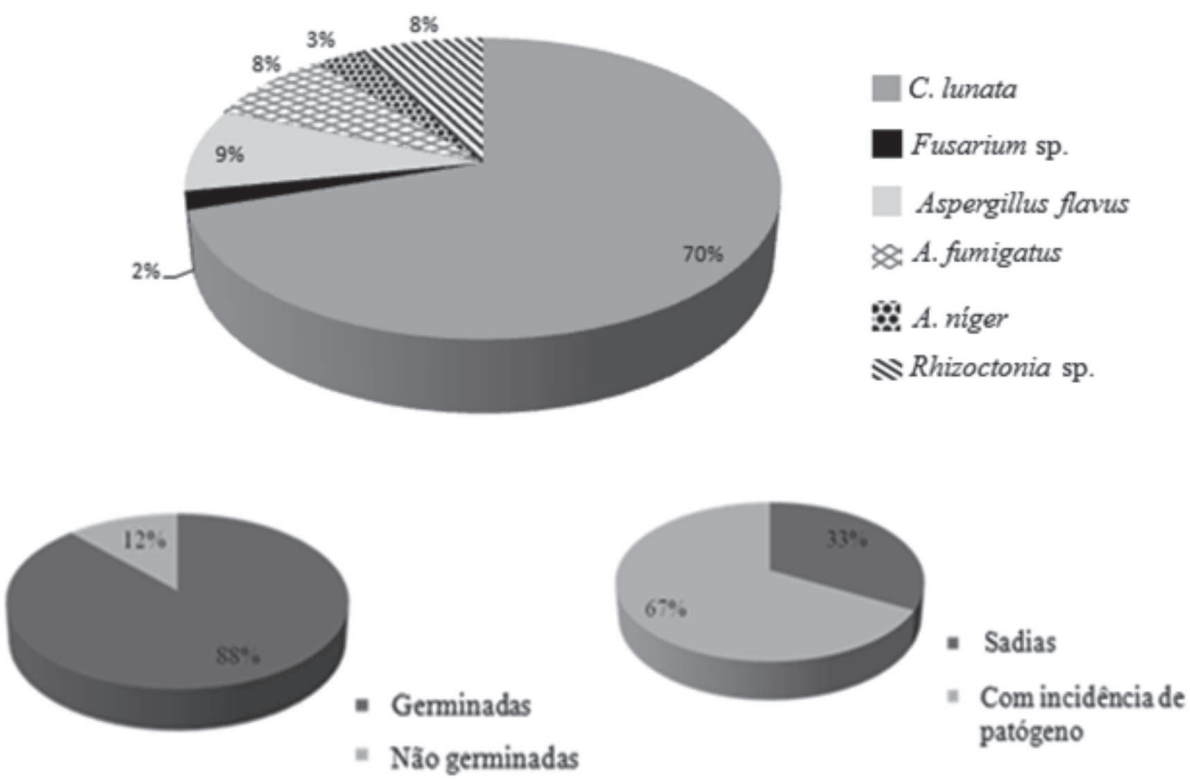

Figura 1. Percentagem de germinação de sementes de arroz 'Bonança' e incidência de patógenos nas sementes infestadas naturalmente e sem tratamento pelo método Blotter test.

Rev. Ceres, Viçosa, v. 61, n.4, p. 511-517, jul/ago, 2014 
Na quantificação da taxa de transmissão, verificou-se que o fungo $C$. lunata foi detectado em todos os órgãos da plântula e nas três épocas de avaliação. As taxas médias de transmissão, nas três épocas, foram de 51,$75 ; 44,16$ e $73,12 \%$, respectivamente, para a raiz primária, colmo e glumas (Tabela 2).

Esses resultados estão de acordo com os de Casa et al. (2005), que afirmaram que o patógeno utiliza-se de órgãos ou de partes do hospedeiro para sua sobrevivência e disseminação. Esta associação garante o acesso direto do parasita à fonte nutricional, por ocasião da germinação e emergência. Estes mesmos autores afirmam ainda que, os patógenos podem ser encontrados, acompanhando, infestando e infectando a semente. Nos casos de infecção, os fungos normalmente se encontram como micélio dormente no pericarpo e no endosperma da semente, o que lhes garante maior eficiência na sobrevivência e na transmissão para plântulas.

Segundo Reis \& Casa (2005), a transmissão do fungo, da semente à plântula, ocorre com alta eficiência, levando à hipótese de que o inóculo vem de fontes externas, próximas e abundantes, como, por exemplo, hospedeiros secundários. Mas, na realidade, a transmissão ocorre por meio da semente.

Durante a avaliação dos isolados de Bacillus no controle da $C$. lunata, em arroz, pode-se observar que, em relação ao número de folhas doentes por vaso, houve diferença significativa entre os tratamentos B22, B12, B35, B16 e B47, em comparação com a testemunha; que no entanto, não diferiram entre si. Já os isolados B22 e B41 não apresentaram diferença significativa, quando compa-

Tabela 1. Teste de patogenicidade de Curvularia lunata isolado de sementes de arroz da variedade Bonança em plantas de arroz dessa mesma variedade

\begin{tabular}{lcc}
\hline Repetição & Severidade & Reação \\
\hline 1 & 8,1 & Susceptível \\
2 & 6,0 & Susceptível \\
3 & 8,2 & Susceptível \\
4 & 10,4 & Susceptível \\
5 & 8,5 & Susceptível \\
\hline
\end{tabular}

Resistente $=$ lesões com cerca de $0,5 \mathrm{~mm}$ de comprimento Intermediário $=$ lesões com $1-2 \mathrm{~mm}$; Susceptível $=$ lesões atingindo 10-20 $\mathrm{mm}$. rados com a testemunha e os demais tratamentos. Com relação ao número de folhas por vaso e ao número de folhas sadias, não houve diferença significativa entre os tratamentos e a testemunha. $\mathrm{O}$ isolado que apresentou o maior percentual de folhas doentes foi o B40, com 28,5\%, diferindo apenas da testemunha, com um percentual de $35,5 \%$; o que apresentou menor percentual foi o isolado B47, com apenas 9,7\% (Tabela 3). A baixa percentagem da incidência do patógeno na testemunha pode ser explicada pelo fato de esse cultivar apresentar certa resistência à doença mancha-de-grãos. Testes de avaliação da resistência, realizados pela Embrapa Amazônia Oriental, mostraram que o cultivar Bonança expressou considerável resistência à brusone, à escaldadura, à mancha-parda e à mancha-de-grãos (Lopes \& Silveira Filho, 2002).

O tamanho da folha, no tratamento B35, diferiu significativamente do tamanho da folha da testemunha. Os demais tratamentos não diferiram significativamente da testemunha, nem entre si. Em relação ao tamanho da lesão, houve diferença significativa entre todos os tratamentos, quando comparados com a testemunha, isto é, todos apresentaram controle sobre o patógeno. Os isolados que mais controlaram foram B41 e B35, com um percentual de 75\%, para ambos (Tabela 4), corroborando os resultados encontrados. Soares et al. (2007), avaliando oito isolados de Bacillus spp., observaram que estes foram capazes de produzir compostos tóxicos inibidores do crescimento micelial dos patógenos Bipolaris oryzae, Gerlachia oryzae (Hashioka e Yologi) W. Gams (Gams e Müller, 1980), Alternaria alternata e Curvularia lunata.

Em ensaios subsequentes, em três anos agrícolas, e conduzidos até a fase de produção, inoculando isolados de Bacillus sp. em plantas de arroz em estádio reprodutivo R3 (emborrachamento), Ludwig et al. (2007) observaram que houve estabilidade do efeito dos antagonistas, além de reduções significativas da severidade da mancha-parda, bem como incrementos significativos da produção.

Segundo Duffy et al. (2003), o efeito do Bacillus sp. sobre os patógenos pode estar relacionado com a produção de enzimas, principalmente as líticas, como quitinases e glucanases, que são utilizados como mecanismos de antagonismo. Por exemplo, Xu et al. (2004) procuraram maximizar a potencialidade do agente de biocontrole $P$. fluorescens (isolamento P5), pela inserção de um gene

Tabela 2. Percentagem de transmissão de $C$. lunata de sementes para plântulas de arroz aos 7,14 e 21 dias após a semeadura

\begin{tabular}{lccc}
\hline \multirow{2}{*}{ Dias após a semeadura } & \multicolumn{3}{c}{ Transmissão (\%) } \\
\cline { 2 - 4 } & Raiz primária & Colmo & Glumas \\
\hline 7 & 21,37 & 25,64 & 51,28 \\
14 & 56,98 & 42,73 & 75,49 \\
21 & 76,92 & 64,10 & 92,59 \\
\hline Média & 51,75 & 44,16 & 73,12 \\
\hline
\end{tabular}


Tabela 3. Avaliação do biocontrole de isolados de Bacillus sp. em folhas de arroz inoculadas com Curvularia lunata

\begin{tabular}{lcccc}
\hline Tratamentos & $\begin{array}{c}\mathbf{N}^{\mathbf{0}} \text { de } \\
\text { Folhas/Vaso }\end{array}$ & $\begin{array}{c}\mathbf{N}^{\mathbf{0}} \text { de Folhas } \\
\text { Sadias/Vaso }\end{array}$ & $\begin{array}{c}\mathbf{N}^{\mathbf{0}} \text { de Folhas } \\
\text { *Doentes/Vaso }\end{array}$ & $\begin{array}{c}\text { Folhas } \\
\text { doentes }(\%)\end{array}$ \\
\hline Testemunha & $77,2 \mathrm{a}$ & $49,8 \mathrm{a}$ & $5,1 \mathrm{a}$ & 35,5 \\
B 22' & $70,0 \mathrm{a}$ & $57,4 \mathrm{a}$ & $3,5 \mathrm{bc}$ & 18,0 \\
B 12 & $58,2 \mathrm{a}$ & $46,4 \mathrm{a}$ & $3,4 \mathrm{bc}$ & 20,3 \\
B 22 & $78,2 \mathrm{a}$ & $62.6 \mathrm{a}$ & $3,9 \mathrm{abc}$ & 19,9 \\
B 7 & $78,6 \mathrm{a}$ & $58,8 \mathrm{a}$ & $4,3 \mathrm{ab}$ & 25,2 \\
B 16 & $72,8 \mathrm{a}$ & $64,8 \mathrm{a}$ & $2,8 \mathrm{c}$ & 9,9 \\
B 47 & $72,4 \mathrm{a}$ & $65,4 \mathrm{a}$ & $2,6 \mathrm{c}$ & 21,9 \\
B 41 & $72,2 \mathrm{a}$ & $56,4 \mathrm{a}$ & $3,9 \mathrm{abc}$ & 15,9 \\
B 35 & $84,0 \mathrm{a}$ & $70,6 \mathrm{a}$ & $3,6 \mathrm{bc}$ & 28,5 \\
B 40 & $72,2 \mathrm{a}$ & $51,6 \mathrm{a}$ & $4,4 \mathrm{ab}$ & 16.97 \\
\hline CV\% & 18.46 & 20.80 & 1.36 & \\
\hline DMS & 28.79 & 25.75 & & \\
\hline
\end{tabular}

Médias seguidas das mesmas letras (na coluna) não diferem entre si, estatisticamente, pelo Teste de Tukey a $5 \%$ de probabilidade. *Dados transformados pela $\sqrt{\mathrm{X}}$. B22' (B. pentothenticus); B7 (Bacillus licheniformes); B12, B35, B40 (Bacillus sp); B16 (B. macerans); B47, B41 (B. cereus); B22 (B. polymyxa).

Tabela 4. Avaliação da mancha foliar causada por C. lunata em plantas de arroz tratadas com Bacillus sp

\begin{tabular}{lccc}
\hline Tratamentos & Tamanho da Folha & *Tamanho da Lesão & Controle (\%) \\
\hline Testemunha & $9,1 \mathrm{a}$ & $2,3 \mathrm{a}$ & - \\
B22 & $8,2 \mathrm{ab}$ & $1,5 \mathrm{~b}$ & 51,8 \\
B 12 & $8,5 \mathrm{ab}$ & $1,6 \mathrm{~b}$ & 50,0 \\
B 22 & $7,9 \mathrm{ab}$ & $1,2 \mathrm{~b}$ & 73,2 \\
B 7 & $7,7 \mathrm{ab}$ & $1,2 \mathrm{~b}$ & 71,4 \\
B 16 & $10,1 \mathrm{a}$ & $1,3 \mathrm{~b}$ & 67,8 \\
B 47 & $8,6 \mathrm{ab}$ & $1,3 \mathrm{~b}$ & 67,8 \\
B 41 & $7,9 \mathrm{ab}$ & $1,2 \mathrm{~b}$ & 75,0 \\
B 35 & $6,4 \mathrm{~b}$ & $1,2 \mathrm{~b}$ & $\mathbf{7 5 , 0}$ \\
B 40 & $8,3 \mathrm{ab}$ & $1,3 \mathrm{~b}$ & 67,8 \\
\hline CV\% & 14.94 & 21.15 & \\
\hline DMS & 2.62 & 0.64 & \\
\hline
\end{tabular}

Médias seguidas das mesmas letras (na coluna) não diferem entre si, estatisticamente, pelo Teste de Tukey a $5 \%$ de probabilidade. *Dados transformados pela $\sqrt{\mathrm{X}}$. B 22' (B. pentothenticus); B 7 (Bacillus licheniformes); B12, B35, B40 (Bacillus sp); B16 (B. macerans); B 47, B41 (B. cereus); B22 (B. polymyxa).

que codifica para síntese de quitinases. O mutante P5-1, com um gene funcional para quitinases, era mais eficiente que o isolamento original P5, no biocontrole de Rhizoctonia solani Kuhn, em arroz e algodão (Gossypium hirsutum L.), e de Gaeumannomyces graminis var. tritici, em trigo (Triticum aestivum L.).

Confirmando ainda os efeitos dos Bacillus, Silva et al. (2004) afirmam que $B$. cereus, uma espécie muito utilizada como agente de biocontrole de doenças de plantas, produz dois antibióticos de largo espectro - zwittermicina e kanosamina - sendo as bactérias insensíveis ao segundo antibiótico.

\section{CONCLUSÕES}

No teste de sanidade, foi detectada maior incidência de C. lunata, apresentando-se patogênico à variedade de arroz Bonança, sendo detectado em todos os órgãos da plântula (raiz primária, colmo e glumas). Em relação ao controle, os isolados de Bacillus que mais se destacaram na mancha foliar foram B41 e B35.

\section{REFERÊNCIAS}

Brasil (2009) Ministério da Agricultura e Reforma Agrária. Ministério de Agricutura e Reforma Agrária. Regras para análise de sementes. Brasília, SNDA/DNVD/CLAV. 398p.

Casa RT, Reis EM \& Moreira EM (2005) Transmissão de fungos em sementes de cereais de inverno e milho: implicações epidemiológicas. In: Zambolin L (Ed.) Sementes: qualidade fitossanitária. Viçosa, Universidade Federal de Viçosa. p.55-74

Dasgupta S, Saha D \& Saha A (2005) Levels of common antigens in determining pathogenicity of Curvularia eragrostidis in different tea varieties. Journal of Applied Microbiology, 98:1084-1092. 
Duffy B, Schouten A \& Raaijmakers JM (2003) Pathogen selfdefense: mechanisms to counteract microbial antagonism. Annual Review of Phytopathology, 41:501-538.

FAO (2004) International year of Rice. Disponível em: <http:// www.fao.org/rice2004/es/concept.htm>. Acessado em: $11 \mathrm{de}$ outubro de 2008

Goulart ACP (1996) Transmissão de Bipoloaris sorokiniana de sementes ao coleóptilo do trigo. Summa Phytopathologica, $22: 5-9$.

Internacional Rice Research Institute (1963) Leaf lesion types of the rice blast disease. In: Internacional Rice Research Institute. The rice blast disease. Baltimore, The John Hopkins Press. $507 \mathrm{p}$.

Kupper KC, Gimenes-Fernandes N \& Goes A (2003) Controle biológico de Colletotrichum acutatum, agente causal da queda prematura dos frutos cítricos. Fitopatologia Brasileira, 28:251257.

Lima A \& Furtado M (2007) Curvularia species (anamorphic fungi: Hyphomycetes) from Santiago island, Cape Vert. Portugaliae Acta Biologica, 22:145-156.

Lopes AM \& Silveira Filho A (2002) Bonança: cultivar de arroz de sequeiro recomendada para a região nordeste do estado do Pará. Ministério da Agricultura, Pecuária e Abastecimento. p.1-4. (Comunicado Técnico, 72).

Ludwig J, Moura AB, Santos AS \& Correa BO (2007) Potencial de isolados bacterianos no biocontrole de doenças na cultura do arroz irrigado. In: $9^{a}$ Reunião Brasileira sobre Controle Biológico de Doenças de Plantas, Campinas. Anais, EMBRAPA/meio ambiente.

Malavolta VMA, Soligo EA, Dias DD, Azzini LE \& Bastos CR (2007) Incidência dos fungos e quantificação de danos em sementes de genótipos de arroz. Summa Phytopathologica, $33: 280-286$

Marassi AC, Barbosa TS, Keller LAM, Rodrigues MAA, Krüger CD \& Rosa CAR (2008) Microbiota isolada de amostras de arroz provenientes do Estado do Maranhão destinadas ao consumo humano, em áreas de ocorrência de beribéri. Revista Ciência Vida, 28:150-152.
Menezes M \& Assis JP (2004) Guia prático de fungos fitopatogênicos. Recife, UFRPE. 106p.

Pinto NFJA (2005) Análise sanitária na produção de sementes de grandes culturas. In: Zambolin L (Ed.) Sementes qualidade fitossanitária. Viçosa, Universidade Federal de Viçosa. p.295332.

Reis EM \& Casa RT (2005) Danos causados por fungos associados a sementes de cereais de inverno. Summa Phytopathologica, $31: 138-140$

Sartori AF, Reis EM \& Casa RT (2005) Quantificação da transmissão de Fusarium moniliforme de sementes para plântulas de milho. Fitopatologia Brasileira, 27:456-458.

Shan FY, SHI W, Liu Y, Zhang J \& Dong J (2008) Parasitic fitness and RAPD analysis of Curvularia species on corn. Journal of Agricultural University of Hebei, 31:37-41.

Silva HAS, Romeiro RS, Macagnan D, Halfeld-Vieira BA, Pereira MCB \& Mounteer A (2004) Rhizobacterial induction of systemic resistance in tomato plants: non-specific protection and increase in enzyme activities. Biological Control, 29:288-295.

Soares VN \& Moura AB (2007) Prospecção por bactérias produtoras de antibióticos ativos contra fungos causadores de manchas foliares em arroz. In: $4^{\circ}$ Congresso Brasileiro de Arroz Irrigado, Pelotas. Anais, UFPel. p.672-674.

Utumi MM \& LOBO VLS (2008) Manchas de grãos no arroz em Goiás, Mato Grosso e Rondônia. Disponível em: <http:// www.portaldoagronegocio.com.br/conteudo.php?id=23721>. Acessado em: 23 de janeiro de 2013.

Xu X, Zhang L, Zhu Y \& Tang W (2004) Improving biocontrol effect of Pseudomonas fluorescens p5 on plant diseases through genetic modification with chitinase gene. Journal of Agricultural Biotechnology, 12:460-463. 